counteracting the damaging effects of ultra-violet radiation is a general phenomenon applying to a wide range of cells. The mechanism is obscure : it may be that changes caused to cell components by ultra. violet radiation are reversed in illuminated cells; but it is equally possible that visible light stimulates synthetic mechanisms that produce new components to replace those damaged. As nucleic acid absorbs ultra-violet radiation strongly, and the effects of irradiation interfere with the multiplication of viruses that are nucleoproteins, it is logical to suspect that, when cells are irradiated with ultra-violet light, at least one of the effects is to disturb the nucleoprotein metabolism. Many active systems of cells depend on components that are sensitive to ultra.violet light, and the evolution of organisms capable of surviving in habitats exposed to sunshine may well have depended on the development of some compensating mechanism. The advantages of a mechanism operated by visible light, when cells are never exposed under natural conditions to intense ultra-violet radiation without simultaneously being exposed to visible light of a high intensity, are too obvious to need stressing. ' Kelner, A., Proc. U.S. Nat. Sci. Acad., 35, 73 (1949).

2 Kelner, A., J. Bact., 58, 511 (1949).

${ }^{3}$ Kelner, A., J. Gen. Physiol., 34, 835 (1951).

Blum, H. F., Loos, G. M., Price, J. P., and Robinson, J. C., Nature, 164, 1011 (1949).

s Dulbecco, R., J. Bact., 59, 329 (1950).

\section{DEFICIENCY DISEASES IN JAPANESE PRISON CAMPS}

$\mathrm{F}^{\mathrm{s}}$ OR much of our knowledge of human metabolic processes we are indebted to small groups of volunteers who have submitted themselves to restricted and unpalatable diets for a fow weeks (less often, months) always knowing that they could withdraw if they wished or if the effects appeared to be too dangerous. Now there has been published* a comprehensive report on the effects of an inadequate, unbalanced and unaccustomed diet, maintained over a period of years, on thousands of men, women and children, prisoners in the hands of the Japanese in Hong Kong and Singapore. There could be no voluntary withdrawal from this 'experiment', and one cannot praise too highly the spirit which led the scientific members of the group not only to alleviate suffering to the best of their ability, but also to record and analyse all those phenomena which might add to the understanding of the mechanisms of malnutrition.

The food available consisted mainly of highly milled rice together with fresh vegetables, small quantitios of beans, sugar and cooking oil, and erratic and meagre supplies of meat or fish. This is quite typical of the poor rice-eater's diet at all times, and those who had studied nutrition in the Far East knew the main problems they would have to face-namely, deficiencies of thiamin and the $\mathrm{B}_{2}$-complex vitamins, possibly complicated by shortages of calcium and proteins as well.

It was, therefore, a primary consideration to devise ways and means of remedying these defects to the greatest possible extent, and groat ingenuity was exercised to this end; "all bones, meat and fish, and

* Mejical Research Council: Special Report Series, No. 274. Defliciency Diseases in Japanese Prison Camps. Bv Dean A. Smith and Michael F. A. Woodruff. (London: H.M. Stationery Office, 1951.) 6s. $6 d$. net. fish scales, fins and tails, were subjected to prolonged pressure cooking ... at times as much as 5 to 7 grams [of the resultant paste] could be provided daily for each person". Yeast was cultured, tough and unpalatable leaves were dried and crushed (6)0 lb. daily in one camp), pine-needles were infused, rice polishings were most carefully utilized, and many attempts were made to make soya beans palatable and digestible, the only satisfactory method proving to be one common in Indonesia, involving inoculation with a fungus. Otherwise, these beans were liable to give rise to much digestive disturbance when used in any quantity, even if first reduced to a fine meal.

Vitamin concentrates were prepared for therapeutic use by crushing and extracting grass and other leaves, by extracting rice polishings, and by the yeast culture already mentioned. An unexpected deficiency in the rations was that of salt, and it became necessary to rely on the use of sea water to make good this lack. Some other ideas which might have proved useful had to be ruled out for lack of fuel, and many that were adopted are as much a tribute to the ingenuity of those men who could make machines out of scrap as to the nutritionist. With all their difficulties, however, these internees succeeded in getting a better balance in their dietary than many a poor Asiatic family does in peace-time. The final paragraph of the report runs as follows: ". . . it is impossible to overestimate the value which a poor diet of the Asiatic type derives from the addition of beans, rice polishings, groundnuts, yeast, and abundant green vegetables. There is no doubt that the comparatively low mortality in the camps ... was due largely to the production, purchase, and careful utilization of these food materials. Notes on the ways in which they were prepared and used are given . . a and, crude as the methods were, they may suggest ideas for large-scale application to orienta dietaries".

In a diet which, in the civilian camps, all too often provided less than 2,000 Calories per head per day, it usually proved possible to keep the intake of thiamin above the 1-mgm. level. In Singapore the riboflavin intake was often reasonably adequate, but in Hong Kong it was rarely above $0.7 \mathrm{mgm}$. and frequently fell below this. Intakes of proteins and of calcium were also lower in the Hong Kong camp, averaging $55 \mathrm{gm}$. and $300 \mathrm{mgm}$. respectively, against Singapore's $70 \mathrm{gm}$. and $450 \mathrm{mgm}$.

There are, of course, many groups of people through. out the world whose food supply only rarely reaches the 2,000-Calorie level; but in these prison camps, with their mainly adult population of comparatively tall people often called upon to perform heavy physical work, energy expenditure could not be reduced sufficiently to prevent a slow, steady destruction of body tissues to meet the deficit which continued long after weights had come down and reserves of fat been used up.

Many different specialists will find material worthy of their detailed consideration in the descriptions of the clinical signs and symptoms which occurred, since it is rare to have available so much information about the diet and environmental conditions of cases presenting similar signs in ordinary life. Some of these signs have already attracted considerable attention, notably the "burning feet syndrome". No less important is the contribution to our knowledge of skin lesions and of changes in the eye brought about by dietary deficiencies. Nevertheless, it is probably the physiologist who has the most to learn 
from a study of this report; many of the statements commonly found in text-books need to be revised in the light of these experiences in particular, we need to think again about protein levels and the causes of cedema.

Perhaps the most heartening paragraph in the whole report is the one dealing with rehabilitation. Although it did not prove possible to organize a follow-up of many people, in those who were seen, "weight recovery was very rapid .... and the only permanent ill-effects detectable were the few irreversible changes in the nervous system, such as spastic paraplegia and optic atrophy. The impression is strong ... that a year after release there were few ex-internees, except those prevented by age, who were not fit to return to duty in the tropics". One would like an assurance that this recovery persisted, and that there were no later breakdowns; especially one would like to have more information about those who spent four years of their childhood under these appalling conditions. About this group the report is singularly silent.

M. W. Grant

\section{MOSCOW CONFERENCE ON THE THEORY OF CHEMICAL STRUCTURE IN ORGANIC CHEMISTRY*}

$T$ HE Conference on the Theory of Chemical Structure in Organic Chemistry, called by the Chemical Science Section of the Academy of Sciences of the U.S.S.R., directs attention to the great importance of the questions that have formed the subject of discussion and have attracted the attention of the whole chemical community of our country. More than four hundred chemists, physicists and philosophers of the Academy of Sciences of the U.S.S.R., of the academies of sciences of individual republics, of scientific research institutes, and of the higher educational institutes of the Soviet Union have taken part in the Conference.

The great activity of the participants has clearly shown that the Conference was opportune and necessary and that the questions raised are of real and immediate importance. The chemists, and also physicists, of our country have not given sufficient attention to the struggle for the establishment of the dialectical-materialism world-view in chemical science and allied branches of physics, in theoretical chemistry and, in particular, in organic chemistry, and, as a result, some Soviet chemists have been ensnared by the unsound, idealistic 'theory' of resonance.

The sterile 'theory' of resonance and the blunders of the Soviet scientists who have developed this unsound conception and applied it in their work were subjected to devastating criticism by the participants of the Conference. The Conference has clearly demonstrated the soundness of the theory of the structure of organic compounds due to the great Russian scientist, A. M. Butlerov; this theory lies at the basis of the whole of modern organic chemistry. The Conference pointed out the urgent necessity of further developing Butlerov's materialistic theory of

* Resolution adopted by the Conference held on June 14, 1951 ; translated from Zhurnal obshchey khimii (Journal of General Chemistry of the U.S.S.R.), 21, 1729 (September 1951), by Dr. A. E. Stubbs. organic compounds and of studying more deeply his works and those of prominent representatives of the famous Butlerov school of organic chemists.

Having considered the report of the Committee of the Chemical Science Section of the Academy of Sciences of the U.S.S.R., the Conference notes that during the period of the Stalin five-year plans there has been created, under the leadership of the Party, of the Government, and of Comrade Stalin personally, a mighty industry of heavy organic synthesis: the first synthetic rubber industry in the world has been created; motor-fuel, synthetic fibre, dye, plastics, and other industries have been created. Recently great progress has been made in the manufacture of complex organic preparations for use in medicine and in the food, textile and other industries. The manufacture has been organized of antibiotics, antimalarials, antituberculosis and other curative preparations, flotation reagents, photosensitizers, insecticides, fungicides, etc.

The Conference notes that the progress of tho organo-chemical industry is bound up with the creative development of organic chemistry in our country. Invaluable contributions to organic chemistry have been made by such discoveries as dehydrogenation catalysis by Zelinsky, the dehydroaromatization of paraffins by Kazansky and Moldavsky, isomeric transformations of unsaturated hydrocarbons by Favorsky, the Demyanov, Nametkin, Kizhner and Arbuzov rearrangements, the Lebedev, Rodionov, Nesmeyanov and other reactions, and also by important theoretical generalizations.

The Conference notes that, side by side with these fruitful trends in the theory of chemical structure, there has been a spread of unsound views that are perversions of Butlerov's teaching. In a number of monographs and taxt-books on inorganic chemistry and the theory of molecular structure, the name of Butlerov, as the creator of structural theory, has been suppressed, and the work of Russian chemists in the development of theoretical organic chemistry has not been assigned its true importance. In recent years there has been a spread in organic chemistry of a concept developed by Anglo-American scientists - the so-called 'theory' of resonance (Pauling) or mesomerism (Ingold). 'This 'theory', which presents a multistructural view of the molecule, is directly opposed to the basic thesis of Butlerov's theory.

Though unsound in method, physically untenable, and sterile, the concept of resonance or mesomerism has unfortunately found supporters among Soviet scientists (such as the following corresponding members of the Academy of Sciences of the U.S.S.R. : Ya. K. Syrkin, M. E. Dyatkina, M. V. Volkenshteyn, A. I. Kiprianov and others). These scientists, in disseminating the mechanistic and idealistic concept of resonance, tried to cover the invalidity of this concept by references to its alleged basis in quantum mechanics and invoked it to explain all the facts and laws of chemistry. The 'theory' of resonence or mesomerism was taken up in an uncritical fashion also by other Soviet scientists indicated in the report. The spreading of this 'theory' has done harm to Soviet chemistry. It has diverted the efforts of chemists into useless, pseudoscientific directions and created a harmful illusion of explaining many facts and laws, which are in reality not explained at all ; it has tried to create an appearance of well-being in the matter of the development of the theory of chemical structure, and, in fact, has held up its further development. 